\title{
Morphological and Molecular (18S rDNA) Phylogeny of Five Species of Weevils in the Tribe Phyllobiini (Coleoptera: Curculionidae: Entiminae) from Turkey ${ }^{1}$
}

\author{
Mahmut Erbey $^{2}$, Vahap Eldem ${ }^{3}$ and Yakup Bakır ${ }^{4}$
}

\begin{abstract}
Five species of weevils in the tribe Phyllobiini (Coleoptera: Curculionidae: Entiminae) [Phyllobius glaucus (Scopoli, 1763); Phyllobius virideaeris (Laicharting, 1781); Parascythropus mirandus Desbrochers, 1875; Oedecnemidius pictus (Steven, 1829); Oedecnemidius saltuarius (Heyden, 1888)] were studied to generate analyses of their relationships. Those interspecific relationships were inferred from morphological characters as well as 18S rDNA sequencing data. Phylogenetic trees based on sequencing data were built with Neighbor Joining (NJ), Maximum Likelihood (ML), and Maximum Parsimony (MP) algorithms; morphology-based trees were created using UPGMA (Unweighted Pair Group Method with Arithmetic Mean). The trees have a similar topology.
\end{abstract}

Key Words: Curculionidae, Phyllobiini, Phyllobiini, morphological characters, molecular characters, phylogeny, congruence of phylogenetic methods, $18 \mathrm{~S}$ rDNA

Members of weevil tribe Phyllobiini Schoenherr, 1833 feed on a variety of plant species placed in the orders Urticales, Salicales, Betulales and Rosales (Pesarini, 1980). Larvae and adults feed on roots, stems, leaves, and fruits. Consequently, they can have a detrimental effect on agricultural crops and forest trees causing significant economic losses (Pesarini, 1980).

The Phyllobiini are widespread beetles distributed in the Palearctic biogeographic region. This group of curculionids has been investigated by Hoffmann (1950), Angelov (1976), Korotyaev and Egorov (1977), Dieckmann (1980), Pesarini (1980), Pişer (2001) as well as Yunakov and Korotyaev (2007). Currently, 120 species belonging to eight genera are recognized. Thirty-four species belonging to eight genera are known to occur in Anatolia (Pesarini, 1980; Lodos, et al., 2003).

Numerous placements of some species in this tribe have been made based mostly on morphological traits. For instance, Hoffmann (1950) subdivided the species of Phyllobius into seven subgenera. Subsequently, Dieckmann (1980) separated Phyllobius into eight subgenera, with Phyllobius pictus and Ph. viridearis placed in the subgenera Phyllerastes and Subphyllobius, respectively, whereas Ph. glaucus was placed in the subgenus Phyllobius. Pesarini (1980) and Lodos et al. (2003) elevated all Dieckmann's subgenera to genera. Three of

\footnotetext{
${ }^{1}$ Submitted on April 28, 2014. Accepted on May 19, 2014. Last revisions received on June 24, 2014.

${ }^{2}$ Department of Biology, Faculty of Art and Science, Ahi Evran University, Kırşehir, Turkey. Email: merbey023@gmail.com.Corresponding Author.

3 Department of Biology, Faculty of Science, İstanbul University, İstanbul, Turkey. E-mail: eldemvahap@gmail.com

${ }^{4}$ Biotec Biotechnology, Krrklareli, Turkey. E-mail: yakupbak@gmail.com
}

DOI: 10.9784/LEB2(2)Erbey.01

Electronically available on July 18, 2014. Mailed on July 16, 2014. 
those genera include the five species of interest in this study: Parascythropus mirandus Desbrochers, 1875, Phyllobius [Ph. glaucus (Scopoli, 1763) and Ph. virideaeris (Laicharting, 1781)], and Oedecnemidius [Oed. pictus (Steven, 1829) and Oed. saltuarius (Heyden, 1888). At the species level, while Dieckmann (1980) and Lodos et al. (2003) placed Phyllobius pictus in Phyllobius, Pesarini (1980) placed Ph. pictus in a different genus, as Oedecnemidius pictus. Also, while Pesarini (1980) removed Parascythropus mirandus from Phyllobius, Lodos et al. (2003) proposed that Par. mirandus belongs in the genus Phyllobius. Because these studies proposed different placements, we decided to combine morphological characters and nucleic acid (DNA) sequencing data to resolve the relationships. As far as we know, this is the first time molecular data have used to study the evolutionary relationships within the Phyllobiini.

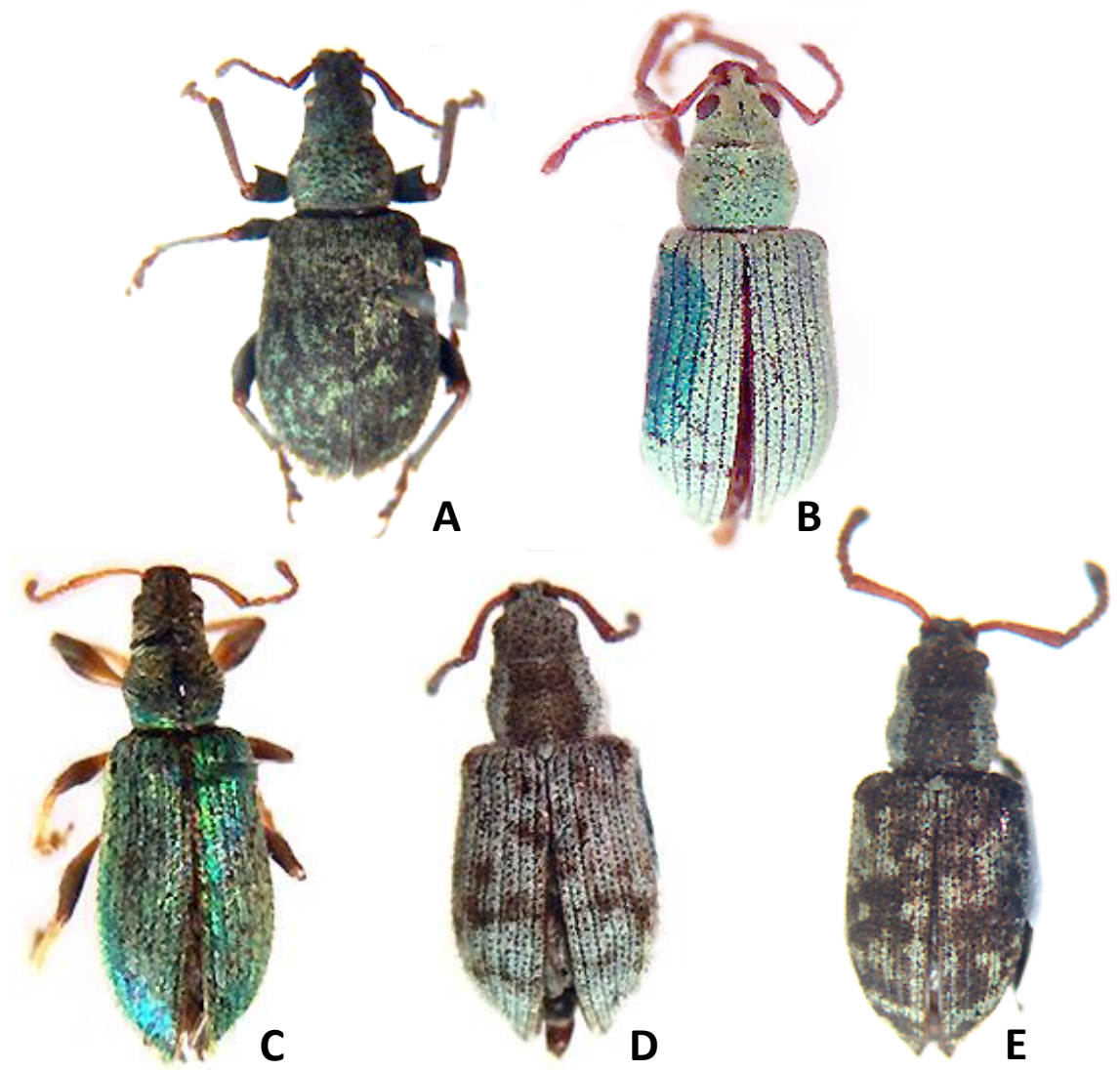

Figure 1. Dorsal view of adults species investigated: A. Phyllobius glaucus, B. Phyllobius virideaeris, C. Parascythropus mirandus, D. Oedecnemidius pictus, and E. Oedecnemidius saltuarius. 


\section{Methods}

In this pilot study, we analyzed the DNA sequence of the $18 \mathrm{~S}$ subunit of the ribosomal DNA, herein abbreviated $18 \mathrm{~S}$ rDNA, of five species of weevils in the tribe Phyllobiini (Coleoptera: Curculionidae: Entiminae): Phyllobius glaucus, Ph. virideaeris, Parascythropus mirandus, Oedecnemidius pictus, and $O$. saltuarius. Also, we analyzed morphological data, selected from identification keys and species descriptions, to further clarify the relationships among the taxa studied. Those genera or species have been directly or indirectly the target of some of the classification changes that have occurred after Hoffman (1950).

At least a dozen specimens of each species were collected in central Anatolia between 2011 and 2012 (Figure 2) and deposited at the Ahi Evran University Zoology Museum Entomology (AUZM-Ent.). A small body part of one specimen per species was used to amplify DNA for the molecular study.

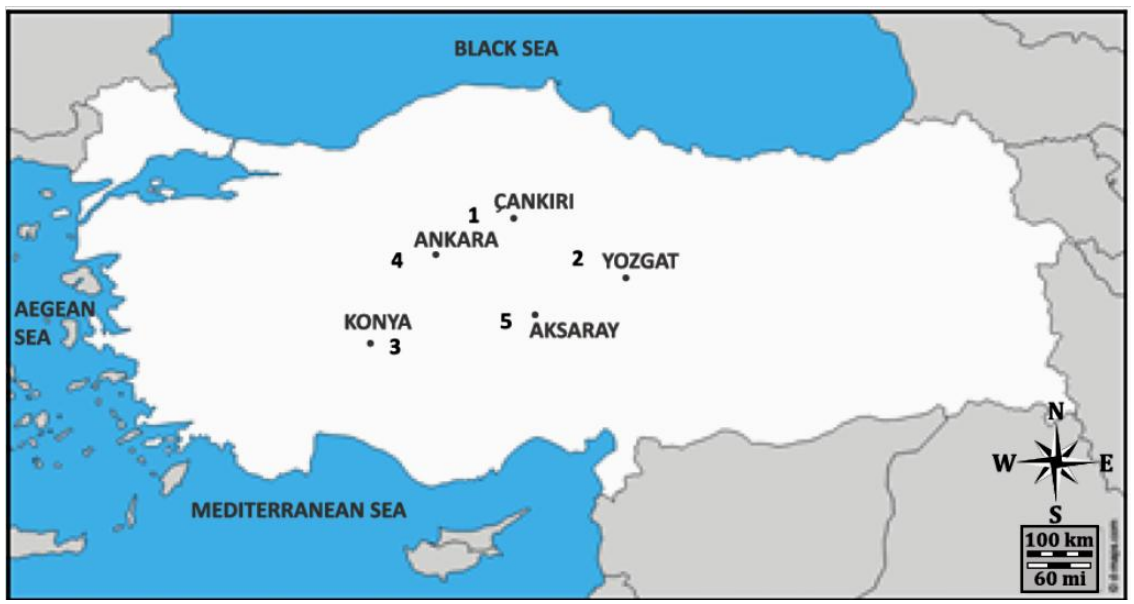

Figure 2. Approximate collection sites of the five species investigated: Phyllobius glaucus (1), Phyllobius virideaeris (2), Parascythropus mirandus (3), Oedecnemidius pictus (4), and Oedecnemidius saltuarius (5). Map taken from http://dmaps.com/carte.php?num car=702\&lang=en , with minor modifications for legibility.

DNA isolation, PCR amplification of 18S rDNA and sequencing. As is commonly done for other organisms, we sequenced the $18 \mathrm{~S}$ subunit of the ribosomal DNA, abbreviated $18 \mathrm{~S}$ rDNA, located in the nucleus, to evaluate the phylogenetic relationships between these five taxa of Phyllobiini. It is generally accepted, however, that the results of phylogenies based on sequencing data are more compelling when they are supported by other types of traits, such as morphological characters.

Total genomic DNA for each species was isolated from whole-organisms using a High Pure PCR Template Preparation kit (Roche, GmbH, Germany) based on the manufacturers' recommendations. A sample, or aliquot, of the 
isolated DNA was evaluated using a NanoDrop 2000 spectrophotometer (Thermo Scientific, Wilmington, Delaware, USA) to evaluate the quality (absorbance ratio) of DNA samples. The integrity of the DNA samples was also verified by agarose gel electrophoresis containing ethidium bromide and visualized with a UV transilluminator (Vilber Lourmat, Marne la Vallée, France). One primer pair (BoF1: CTCAGTACAAGCCAAATTAAGG) and (BoR1: CAGTATTCAGGCGAAGTTTTAG) was synthesized for determining the partial sequence of $18 \mathrm{~S}$ rDNA. These primers were subjected to Primer3 Input software (http://frodo.wi.mit.edu/primer3/). The PCR was performed using a TC-5000 gradient thermal cycler (Techne, Stone, Staffordshire, UK) in $50 \mu \mathrm{l}$ reaction volumes containing $31.6 \mu \mathrm{l}$ sterilized deinonized water, $0.4 \mu \mathrm{l}$ ExTaq polymerase (5 U/ $\mu$ l Takara), $5 \mu \mathrm{l}$ Ex Taq buffer (Takara), $2 \mu \mathrm{MgCl}_{2}(25 \mathrm{mM})$, $5 \mu \mathrm{dNTP} \operatorname{mix}(2.5 \mathrm{mM}$ each), $2 \mu \mathrm{l}$ forward primer $(10 \mathrm{pmol}), 2 \mu \mathrm{l}$ reverse primer $(10 \mathrm{pmol})$ and a $2 \mu \mathrm{l}$ template containing approximately $100 \mathrm{ng}$ DNA under the following conditions: one cycle of an initial denaturation at $94{ }^{\circ} \mathrm{C}$ for $5 \mathrm{~min}, 35$ cycles of $30 \mathrm{~s}$ denaturation at $94{ }^{\circ} \mathrm{C}, 1 \mathrm{~min}$ annealing at $54-56{ }^{\circ} \mathrm{C}$ and 1.5 min extension at $72{ }^{\circ} \mathrm{C}$ and followed by $10 \mathrm{~min}$ final extension at $72{ }^{\circ} \mathrm{C}$. The amplicons were separated and evaluated by electrophoresis in $2 \%$ agarose gel with a negative control using $1 \mathrm{X}$ TBE buffer. The amplicons were purified by using a High Pure PCR product purification kit (Roche Applied Science) following the supplier's instructions. The purified products were directly sequenced on an automated sequencer at the BioBasic sequencing facility (Shanghai, China). These PCR primers and all the amplicons were sequenced in both directions. The average amplicon size was $720 \mathrm{bp}$.

Sequence analysis and phylogenetic tree construction. The nucleotide sequences of $18 \mathrm{~S}$ rDNA were used to determine the phylogenetic relationships of five species in the Phyllobiini (parenthetical number refers to repository in GenBank: Phyllobius glaucus (KJ748491), Phyllobius virideaeris (KJ748487), Parascythropus mirandus (KJ748489), Oedecnemidius pictus (KJ748492), and Oedecnemidius saltuarius (KJ748488). The 18S rDNA were analyzed and aligned in BioEditv7.1.3 using the ClustalW multiple sequence alignment method (Hall, 1999). Three fundamentally different, yet widely used, phylogenetic inference approaches, namely, Neighbor Joining (NJ), Maximum Likelihood (ML) and Maximum Parsimony (MP) were used to reveal phylogenetic relationships. Within each method, we tried different models and noticed no significant differences among the trees generated. All of these analyses were performed using MEGA v5 software (Tamura et al., 2011). 


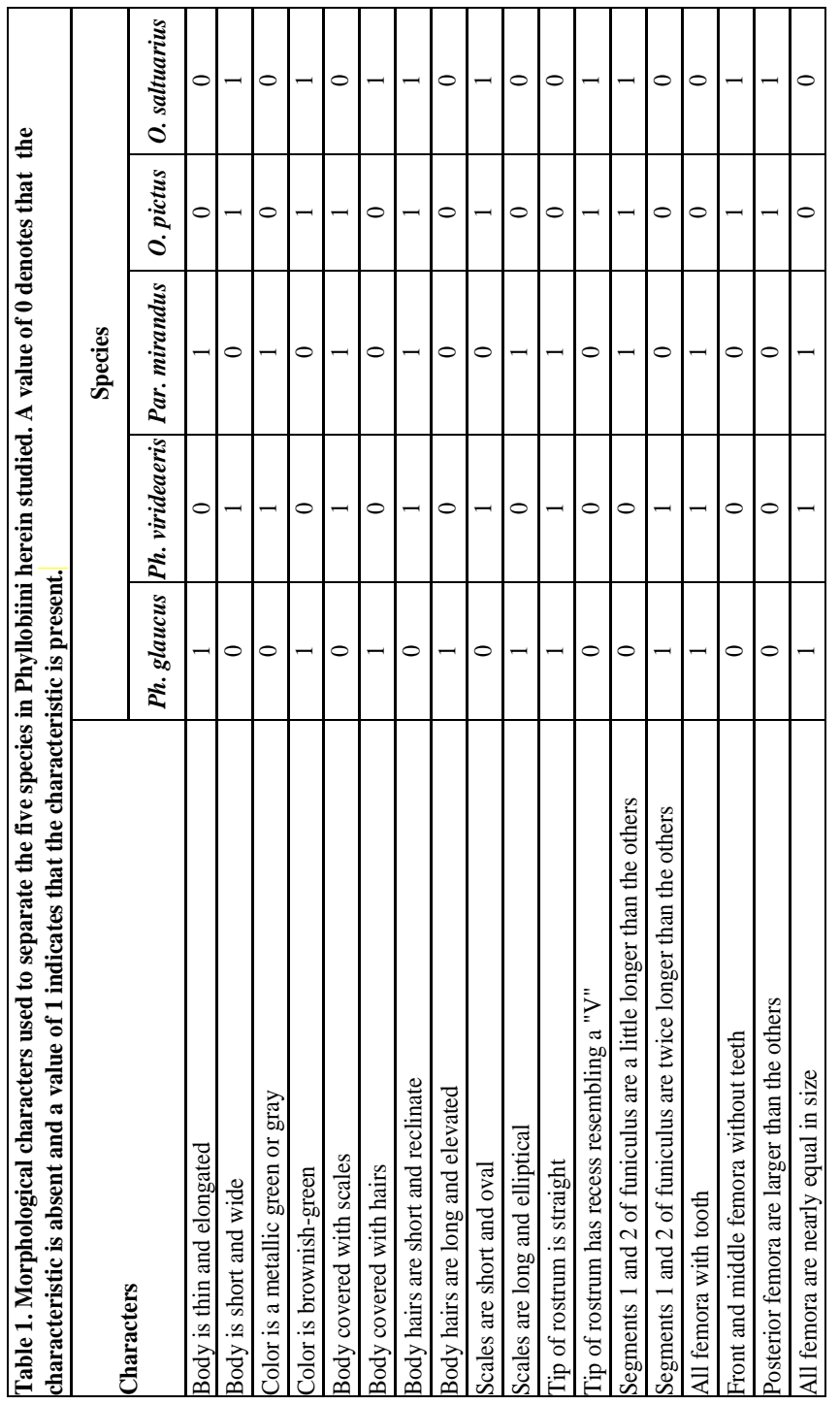


The NJ tree was constructed based on the Kimura-2 parameter model. The MP tree was obtained using the Subtree-Pruning-Regrafting (SPR) algorithm. The ML tree reconstruction was generated using the Jones-Taylor-Thornton (JTT) amino acid substitution model. The rates among sites were set in a gamma distribution within variant sites $(\mathrm{G}+\mathrm{I})$ and then nearest neighbor interchange was selected as the maximum likelihood heuristic method. The statistical confidence of the trees was established by bootstrap analysis with 1000 replications.

Relationships using on morphological characters. Specimens were examined with a light microscope to identify morphological characters for the analyses. Thereafter, the characters chosen were designated 0 , for absent, and 1 for present. These characters, in a form of a data matrix, were entered into NTSYS (2.1), a program for phenetic analyses, to obtain a dendrogram using the UPGMA (Unweighted Pair Group Method with Arithmetic Mean) algorithm. The data matrix used for the phylogenetic relationships using morphological characters is presented in Table 1 . Weevil nomenclature and classification used herein follows Alonso-Zarazaga and Lyal (1999) and Pesarini (1980).

\section{Results and Discussion}

Our analyses support the systematic placement suggested by Pesarini (1980) and Lodos et al. (2003). As shown in the UPGMA dendrogram (Figure 3), Phyllobius glaucus and Ph. virideaeris cluster together. Parascythropus mirandus is a sister taxon to the species of Phyllobius studied even though it does not resemble them morphologically. Furthermore, Oedecnemidius pictus and Oed. saltuarius are morphologically different from both Phyllobius and Parascythropus. This result is consistent with previous findings proposing Oedecnemidius as a distinct genus in tribe Phyllobiini (Pesarini, 1980; Lodos et al., 2003).

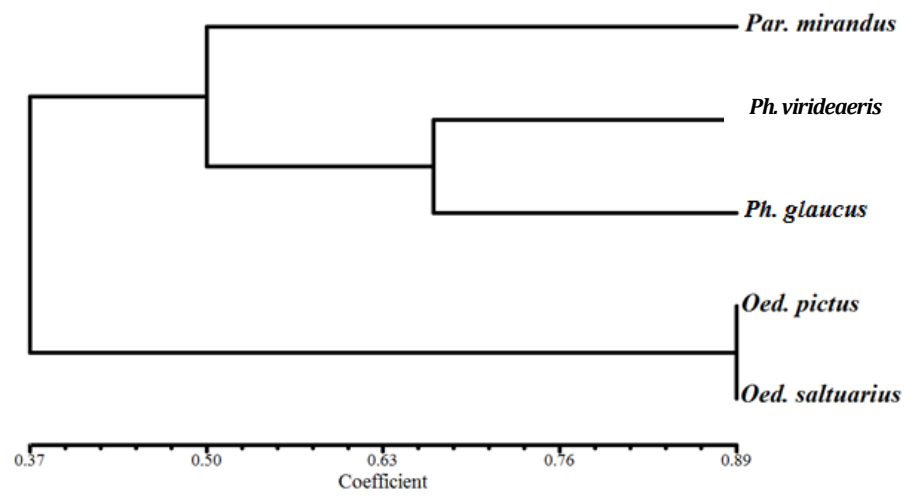

Figure 3. Phenetic relationships between five species of weevils (Phyllobius glaucus, Ph. virideaeris, Parascythropus mirandus, Oedecnemidius pictus, and Oed. saltuarius) in the tribe Phyllobiini (Coleoptera: Curculionidae), using morphological characters (NTSYSpc.2.1 (http://www.exetersoftware.com/downloads/ntsysguide21.pdf). 
The tree constructed based on ML/MP/NJ algorithms and the morphologybased tree generated with UPGMA yield trees sharing the same shape, or topology. Phyllobius (Ph. glaucus and Ph. virideaeris) and Oedecnemidius (Oed. pictus and Oed. saltuarius) are clustered together with a high confidence value (Figure 4). In parallel with the UPGMA tree, Parascythropus mirandus is separated from Phyllobius and Oedecnemidius, suggesting that its placement in its own genus is justified.
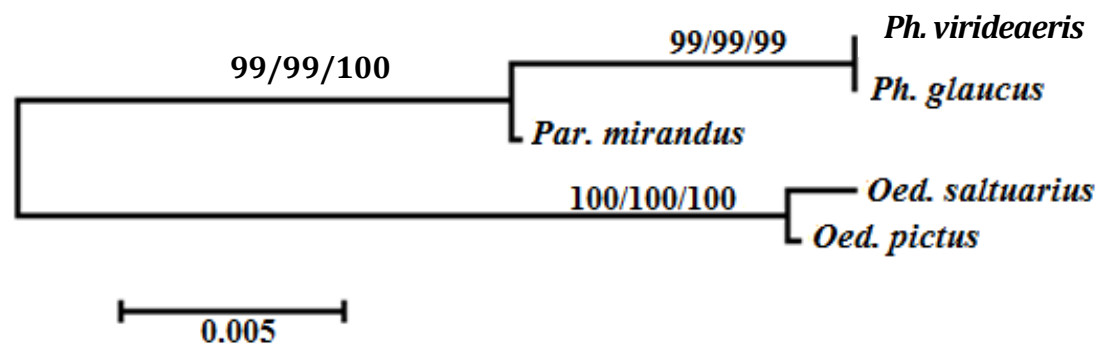

Figure 4. Phylogenetic relationship of five Phyllobiini species (Phyllobius glaucus, $P$. virideaeris, Parascythropus mirandus, Oedecnemidius pictus, Oed. saltuarius). ML/MP/NJ analyses were performed using MEGA.5 software based on the nucleic acid sequences of $18 \mathrm{~S}$ rDNA.

Because only five species were analyzed in this pilot study, additional investigations will help to establish clearer trends within the Phyllobiini and to determine the status of other taxa in the subfamily Entiminae.

\section{Literature Cited}

Alonso-Zarazaga, R. S. and C. H. C. Lyal. 1999. A world catalogue of families and genera of Curculionoidea (Insecta: Coleoptera) (excepting Scolytidae and Platypodidae). Entomopraxis (Barcelona, Spain). 315 pp.

Angelov, P. 1976. Fauna Bulgarica 5. Coleoptera, Curculionidae, Part I (Apioninae, Otiorhynchinae). Aedius Academiae Scientiarium Bulgaricae. Sofya, Bulgaria. 356 pp.

Dieckmann, L. 1980. Beitrage zur insekten fauna der DDR: Coleoptera-Curculionidae (Brachycerinae, Otiorrhynchinae, Brachyderinae). Beitrage zur Entomologia (Berlin) 30:145310 .

Hall, T. A. 1999. BioEdit: a user-friendly biological sequence alignment editor and analysis program for Windows 95/98/NT. pp. 95-98. Nucleic Acids Symposium Series (Oxford, England, UK) 41:95-98. http://jwbrown.mbio.ncsu.edu/JWB/papers/1999Hall1.pdf

Hoffmann, A. 1950. Faune de France, Coleopteres, Curculionides. Premiere Partie. Paris, France. 486 pp.

Korotyaev, B. A. and A. B. Egorov. 1977. Review of the weevil genus Phyllobius Germ. (Coleoptera, Curculionidae) from East Siberia, Far East of the USSR and Mongolia, with remarks on species from other regions. pp. 379-449. In, Insects of Mongolia. Volume 5. Nauka. Leningrad, USSR. 757 pp.

Lodos, N., F. Önder, E. Pehlivan, R. Atalay, E, Erkin, Y. Karsavuran, S. Tezcan, and S. Aksoy. 2003. Faunistic studies on Curculionidae (Coleoptera) of western Black Sea, central Anatolia and Mediterranean regions of Turkey. Meta Basım Matbaa Hizmetleri. İzmir, Turkey. 83 pp.

Pesarini, C. 1980. Le specie paleartiche occidentalli della tribü Phyllobiini (Coleoptera: Curculionidae). Bulletion Zoologia Agraria Bachicolture 15:49-230. 
Pişer, B. 2001. Balıkesir ormanlarinda zararli olan Phyllobius cinsine ait türler üzerinde sistematik arastirmalar" Balıkesir üniversitesi, Fen bilimleri enstitüsü. (In Turkish). Systematic researches on species of the genus Phyllobius (Coleoptera: Curculionidae) that damage forest plants in Balıkesir. Balıkesir University Sciences Instituti (Turkey). $45 \mathrm{pp}$.

Tamura, K., Peterson, D., Peterson, N., Stecher, G., Nei, M. and S. Kumar. 2011. MEGA5: molecular evolutionary genetics analysis using maximum likelihood, evolutionary distance, and maximum parsimony methods. Molecular Biology and Evolution 28:2731-2739. http://dx.doi.org/10.1093/molbev/msr121

Yunakov, N. N. and B. A. Korotyaev. 2007. A review of the weevil subgenus Metaphyllobius Smirnov (Coleoptera, Curculionidae, Entiminae) from Eastern Europe and Siberia. Entomological Review 87:1045-1059. http://dx.doi.org/10.1134/S0013873807080106 